\title{
FRCR 2B Viva: A case-based approach
}

Authors: Paul S Sidhu, Suzanne M Ryan, Philip FC Lung

Publisher: Thieme Publications Stuttgart

Year: 2013

Pages: 302 pages

ISBN: 978-3-13-166291-0

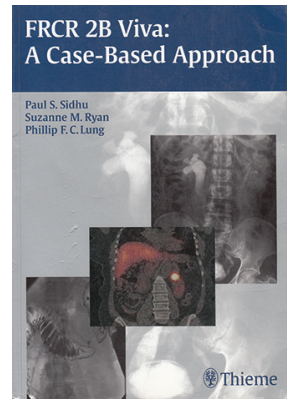

How to present a case and interact with examiner in a Radiology viva? Many consultants teach this aspect to residents in their own department or other exam oriented teaching sessions. Finally, there is a book that does the same. This is perhaps a unique effort among the exam preparatory books; this one helps in viva preparation by printing the actual verbal sentences that can be accepted as ideal presentation for the given case.

The book starts with introduction to the FRCR 2B viva for the candidates and it gives some important information that has been said for years - to quote from the book - "no substitute for hard work," "examination is a game and play the game right and you will pass." The components of the viva are actually broken down from the point of view of the candidate and the examiner; it also gives important well-rounded information regarding how to deal with the whole event.

The book is divided into sections based on systems covering gastrointestinal, chest, musculoskeletal, neurological, urogynecological, pediatric, and head and neck imaging. Each section has many cases that are contributed by a specialist registrar in training who has completed the exam and supervised by a consultant radiologist, specializing in the particular system.

Each system-based division begins with introduction which includes how to approach each film from plain radiographs to MRI; it also tells how to be methodical in approach during the discussion.
There are total 136 sample cases; each case has few images followed by a typical ideal description as one is expected in the viva. This is followed by examination tips, differential diagnosis, and notes. There are also few relevant bibliographies given for further reading in each case.

The images are of high quality and there are emergency cases in every system plus the bread and butter examination films.

This book is not indented to be a complete review of most cases that one can expect in every exam viva; however, this book achieves its aim - providing an ideal, methodical approach and technique of presenting the case to the examiner in a viva examination. Overall, this book is highly recommended for those taking FRCR 2B viva examination; those taking MD/DNB/DMRD and other boards would also find it a very valuable tool.

A Anbarasu

SRL Diagnostics Hitech Scan centre, 178 Bhasyakaralu street RS puram, Coimbatore, TN, India. E-mail: aanbarasu@gmail.com

\begin{tabular}{|l|l|}
\hline \multicolumn{2}{|c|}{ Access this article online } \\
\hline Quick Response Code: \\
\hline
\end{tabular}

